\title{
Identification and Characterization of Neurons Initiating Patterned Neural Activity in the Buccal Ganglia of Aplysia
}

\author{
Abraham J. Susswein ${ }^{1,2}$ and John H. Byrne ${ }^{1}$ \\ 'Department of Neurobiology and Anatomy, University of Texas Medical School, Houston, Texas 77225, and ${ }^{2 D e p a r t m e n t}$ \\ of Life Sciences, Bar-llan University, Ramat Gan 52 100, Israel
}

\begin{abstract}
Two patterns of neural activity were identified in excised buccal ganglia of Aplysia californica. Both are expressed in many cells, and each can be expressed independently. Using cells B4 and B5 as monitors of the activity patterns, we searched the buccal ganglia for cells initiating the patterns. Two electrically coupled cells, B31 and B32, can initiate what we termed pattern 2 . The cells are active before pattern 2 is expressed. Stimuli initiating pattern 2 excite B31/B32. Depolarizing B31/B32 induces the pattern, while hyperpolarizing them can prevent its expression. The cells have unusual features. Their somata do not sustain conventional action potentials, and depolarization causes a regenerative response. $B 33$ differs from $B 31 / B 32$ in that its soma sustains conventional action potentials but otherwise has similar features. B34 also seems to be inexcitable but has weaker synaptic input than B31/B32 and appears unable to induce pattern 2. B35 and B36 have prominent regenerative capabilities. B35 is also able to initiate pattern 2. B37 is presynaptic to B31/B32 and can initiate pattern 2 via its effects on them. The newly identified cells provide a starting point for investigating factors that initiate and control different patterns of neural activity in the buccal ganglia. Since the buccal ganglia are involved in generating feeding behavior, further studies on the newly identified cells may provide insights into the neural control of feeding behavior, and provide a neural substrate for studying modulation of the feeding patterns by associative learning.
\end{abstract}

Feeding in Aplysia is a useful system for investigating neural mechanisms of associative learning (Susswein and Schwarz, 1983; Schwarz and Susswein, 1986; Susswein et al., 1986; Schwarz et al., 1988), and other forms of behavioral plasticity (Kupfermann and Pinsker, 1968; Kupfermann, 1974a; Susswein and Kupfermann, 1975a, b; Susswein et al., 1976, 1978; Weiss et al., 1981). While much is known about sensory, motor and modulatory neurons in the feeding motor system (Cohen et al., 1978; Weiss et al., 1978; Fiore and Meunier, 1979; Rosen et al., 1979, 1982; Jahan-Parwar and Fredman, 1983; Jahan-Parwar et al., 1983;

\footnotetext{
Received Apr. 13, 1987; revised Sept. 15, 1987; accepted Oct. 20, 1987.

We thank Dr. L. Cleary for his comments on an earlier draft of the manuscript. This work was sponsored by the Air Force Office of Scientific Research, Air Force Command, USAF, under Grants AFOSR 84-0214 and 87-NL-020, National Institute of Mental Health Award KO2 MH 00649, and U.S.-Israel Binational Science Foundation Grant 84-00225.

Correspondence should be addressed to Dr. John H. Byrne, Department of Neurobiology and Anatomy, University of Texas Medical School, P.O. Box 20708, Houston, TX 77025.

Copyright (C) 1988 Society for Neuroscience $0270-6474 / 88 / 062049-13 \$ 02.00 / 0$
}

Lloyd et al., 1984), little is known about command neurons and pattern generators initiating feeding. As a first step in addressing this issue, we have sought to identify neurons that control the generation of patterned activity in the buccal ganglia, which may be responsible for generating feeding movements.

Our approach was to characterize patterned neural activity in the isolated buccal ganglia and then find cells initiating the patterns. We used identified cells B4 and B5 (Gardner, 1977; Gardner and Kandel, 1977) as monitors of activity. B4 and B5 were chosen since previous studies showed that they receive inputs from many cells (Rosen et al., 1982) and in turn have widespread effects on other cells in the buccal ganglia (Gardner, 1977; Gardner and Kandel, 1977; Fiore and Meunier, 1979). B4 and B5 are identical in all of their properties, except that they innervate different groups of muscles. In this report we treat the 2 cells interchangeably.

We found that 2 activity patterns are readily identified in the isolated buccal ganglia of $A p l y s i a$. In addition to occurring spontaneously, one pattern is elicited by nerve stimulation. We identified a group of neurons whose activity seems crucial to initiate one pattern. The neurons are characterized by a high degree of electrical coupling and by unique properties that have not been observed previously in the Aplysia nervous system. The properties may be related to the function of these cells as initiators of patterned activity. A preliminary report of some of this work has appeared (Susswein and Byrne, 1986).

\section{Materials and Methods}

Experiments were performed on Aplysia californica obtained from Marinus, Inc. (Westchester, CA) and Marine Specimens Unlimited (Pacific Palisades, CA). Animals were maintained in filtered artificial seawater (ASW) at $15^{\circ} \mathrm{C}$. The data below are based on observations in 130 experiments.

Prior to dissection, animals were anesthetized by injecting into the hemocoel a volume of isotonic $\mathrm{MgCl}_{2}$ equal to $25-50 \%$ of the body volume. Either the isolated buccal ganglia or the buccal ganglia attached to the cerebral ganglion via the cerebrobuccal connectives were then removed from animals. No difference in patterned activity was found between preparations having or lacking the cerebral ganglion. Relatively long lengths of the buccal nerves were removed with the ganglia, so that electrical stimulation of individual nerves could be used to examine patterns of synaptic input to newly identified cells. Ganglia were then placed in a chamber filled with $50 \% \mathrm{ASW}$ and $50 \%$ isotonic $\mathrm{MgCl}_{2}$. The connective tissue sheath overlying the neurons was then surgically removed. Following the dissection, the bathing solution was replaced with ASW buffered to pII 7.6 with Tris. In different experiments, both the rostral and caudal surfaces of the buccal ganglia were explored, but sampling was more extensive on the caudal surface (Fig. 1). Intracellular recording and stimulation were performed at room temperature (22$24^{\circ} \mathrm{C}$ ) using conventional electrophysiological techniques. Measurements of the frequency and amplitude of the various patterns of activity 
Figure 1. Sketch of the caudal surface of one buccal ganglion showing the approximate locations of the cells examined.

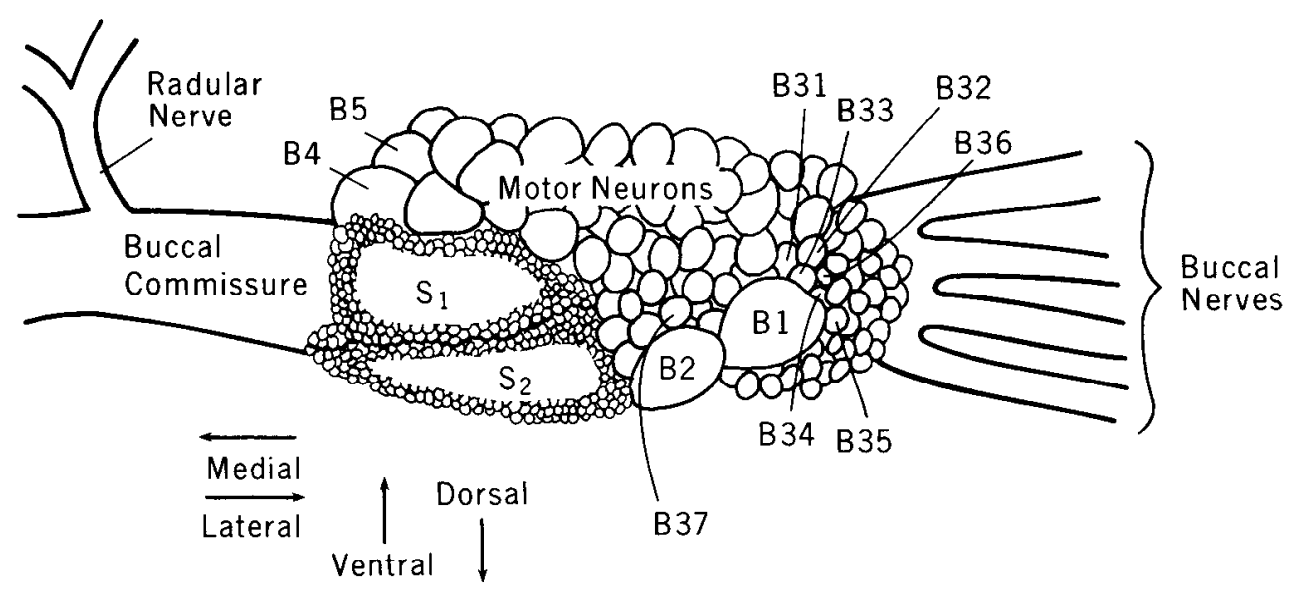

expressed in cells B4 and B5 were usually performed at the start of experiments.

\section{Results}

Burst patterns in the buccal ganglia

Burst patterns in cells B4 and B5 and other buccal motor neurons

Two well-defined activity patterns are expressed in identified cell B4 (Fig. 2A). The first pattern (pattern 1) was seen in 72/ 130 experiments. It is characterized by a rhythmic depolarization of B4 and B5 lasting 0.5-3 sec that is often sufficient to produce action potentials. In many preparations the pattern was constant for long periods of time, while in others the rhythm

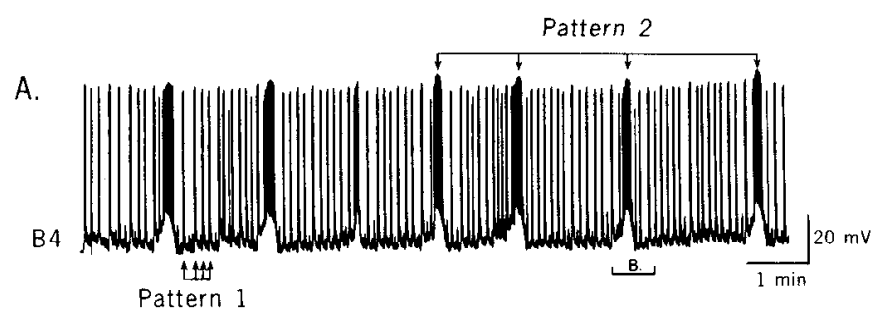

B.

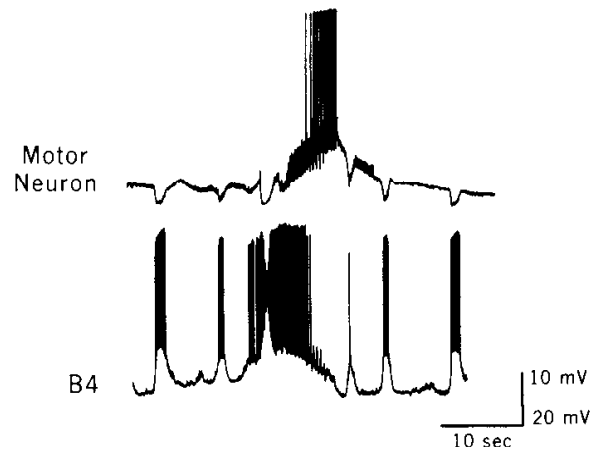

Figure 2. A, Spontaneous expression of 2 patterns of burst activity in B4. Occurrences of the patterns are marked. The expression of pattern 1 occurs at a faster frequency and is associated with a smaller depolarization than pattern 2. $B$. Faster sweep speed of a portion of the record in $\mathcal{A}$ (the segment underlined) to show in greater detail the appearance of the 2 burst patterns. In addition to recording from B4, a recording was also made from a cell in the motor neuron region of the buccal ganglion. The recording shows that expression of pattern 2 in B4 often leads to a "butterfly" appearance of the discharge. The motor neuron hyperpolarizes in phase with the expression of pattern 1 in B4 but becomes depolarized and then fires in the latter portion of the expression of pattern 2 in B4. gradually became weaker during the experiment and eventually ceased. To quantify the frequency and amplitude of the depolarization, the number of events occurring in a period of 2-5 min was counted, in every preparation showing the pattern, and the peak amplitude of the depolarizing envelope underlying the spikes was estimated. The mean frequency of occurrence of pattern 1 was $19.3 \pm 14.6(\mathrm{SD}) / \mathrm{min}$ and the mean amplitude was $6.4 \pm 3.5(\mathrm{SD}) \mathrm{mV}$.

Pattern 2 was seen in 103/130 preparations. In cells B4 and B5 the pattern is characterized by a burst of action potentials superimposed on a sustained depolarization. The depolarization is sometimes sufficiently large that action potentials are partially inactivated, producing a "butterfly" appearance (see Fig. $2 B$, which represents a portion of the trace in Fig. $2 A$ at a faster sweep speed). In 12 of the 103 experiments exhibiting pattern 2 (e.g., Fig. $2 A$ ), the pattern occurred spontaneously and was fairly regular. It occurred at frequencies ranging from $0.5 / \mathrm{min}$ to $5 / \mathrm{min}$. Rhythmic firing associated with pattern 2 activity was usually expressed for no more than 5-10 min. In 57 experiments pattern 2 occurred spontaneously, but very erratically. In addition to occurring spontaneously, pattern 2 could be reliably elicited by stimulation of various buccal nerves or intracellular stimulation of various cells in the buccal ganglia (see below). In 34 preparations, pattern 2 was seen only when elicited by nerve or intracellular stimulation. There was considerable variability in the extent that B4 was depolarized, and in the number of spikes elicited, when pattern 2 was expressed. We compared the mean peak amplitude of the depolarizing envelope underlying 2-5 bursts of activity in preparations that were regular, erratic, or in which pattern 2 activity could be obtained only by extrinsic stimulation. The mean amplitude of the depolarizing envelope was $24.3 \pm 11.6(\mathrm{SD}) \mathrm{mV}$ in regular preparations, $20.1 \pm 8.1$ (SD) $\mathrm{mV}$ in erratic preparations, and $20.3 \pm 7.2$ (SD) $\mathrm{mV}$ in preparations in which activity was exclusively evoked. These results indicate that the depolarization underlying pattern 2 is similar in all types of preparations and that it is considerably larger than that for pattern 1 (see above).

The ventral portion of the buccal ganglia is almost entirely composed of large cells that are identified motor neurons for specific buccal muscles (Weiss, Cohen, Cropper, and Kupfermann, personal communication). The activity in these motor neurons correlated with the expression of patterns 1 and 2 in B4 differed from cell to cell. Some motor neurons were excited during expression of both patterns, while other motor neurons were inhibited during expression of pattern 1 but excited during 
A.

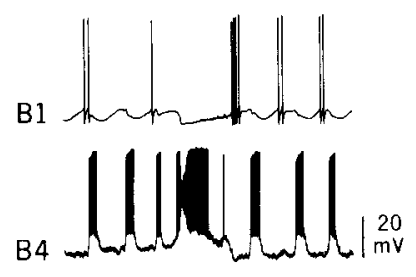

B.

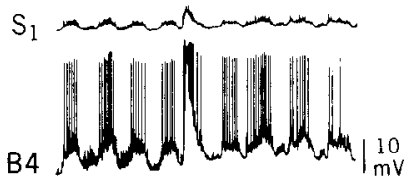

C.

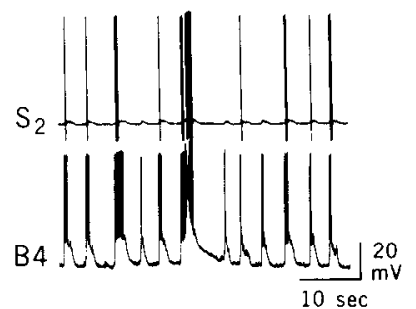

Figure 3. Spontaneous expression of patterns 1 and 2 monitored in a number of different cell types in the buccal ganglia. A, Appearance of the 2 activity patterns in identified cells B1 and B4. During expression of both patterns in B4, B1 was hyperpolarized. Note also that B1 fires 1 or 2 action potentials preceding the depolarization associated with pattern 1 in B4. This spike activity in B1 was not temporally associated with expression of either pattern in B4. B, Activity in B4 and an $\mathrm{S}_{1}$ cell. The $\mathrm{S}_{1}$ cell is weakly depolarized in phase with the bursts of spikes in B4 but does not fire. $C$, Activity in B4 and an $S_{2}$ cell. Weak firing in the $S_{2}$ cell occurs in phase with the expression of both patterns in B4.

pattern 2. The upper trace in Figure $2 B$ illustrates the expression of patterns 1 and 2 in a motor neuron that was inhibited in phase with expression of pattern 1 in B4 and excited after pattern 2.

Virtually all cells in the motor neuron cluster are monosynaptically driven by cells B4 and B5. Most receive IPSPs from B4 and B5 (Gardner, 1977; Cohen et al., 1978; Fiore and Meunier, 1979), but some receive EPSPs, or mixed excitatory-inhibitory drive (Gardner and Kandel, 1977). It was of interest to determine whether these neurons are independently driven by the pattern generators driving B4 and B5 or whether the patterns are expressed in the motor neurons via input from $B 4$ and $\mathrm{B} 5$. In the preparation shown in Figure $2 B$, intracellular stimulation of $\mathrm{B} 4$ to mimic its firing during pattern 2 produced neither the excitatory nor the inhibitory drive in the motor neuron characteristic of hurst activity (not shown). These data suggest that expression of both patterns in the motor neurons can be independent of direct synaptic input from B4. In some cells in the motor neuron region, synaptic input from B4 and a pattern generator were simultaneously evident, and were clearly different. Both cells were depolarized by spontaneous bursts, but superimposed on the depolarization were monosynaptic IPSPs from B4.

\section{Burst patterns in other buccal ganglia cells}

To characterize the burst patterns in greater detail, we examined whether the patterns seen in B4 and B5 are also expressed in a number of different classes of cells in the buccal ganglia.

Burst pattern in B1 and B2. Cells B1 and B2 are the largest cells in the buccal ganglia. In 7 preparations, such as that shown in Figure $3 A$, $\mathrm{B} 1$ fired 1 or 2 action potentials preceding expression of pattern 1 in $\mathrm{B} 4$ and then was weakly hyperpolarized during and after the spike burst in B4. In 2 preparations B1 was unaffected during expression of pattern 1 in B4. In all preparations, a strong hyperpolarization in $\mathrm{B} 1$ was simultaneous with the expression of pattern 2 in B4. These observations confirm previous data by Fiore and Meunier (1979) that B1 and B2 (which they termed the $C$ cells) are inhibited during bursts of activity in the buccal ganglia, while $\mathrm{B} 4$ and $\mathrm{B} 5$ are excited.

Burst patterns in the $S_{1}$ and $S_{2}$ cells. Just dorsal to cells B4 and $B 5$ are the $S_{1}$ and $S_{2}$ clusters, 2 populations of small cells (Fiore and Meunier, 1979). We examined the activities of these cells during patterned buccal ganglia activity since previous studies (Fiore and Meunier, 1979) indicated that they excite B4 and B5 and inhibit B1. Fiore and Meunier (1979) suggested that activity of the $S_{1}$ cells might drive the burst patterns in the buccal ganglia.

In 5 experiments in which B4 spontaneously exhibited one or both patterns, $8 \mathrm{~S}_{1}$ cells were recorded. These depolarized in phase with $B 4$, but the depolarizations were not sufficient to fire action potentials (Fig. $3 B$ ). Twelve $S_{1}$ cells were fired with depolarizing current pulses while recording from $B 4$. In 8 of these, 1 -for-1 EPSPs in B4 were seen, but the EPSPs rapidly decremented (not shown). In 11 experiments spontaneously exhibiting one or both patterns, $33 \mathrm{~S}_{2}$ cells were recorded along with B4. The $S_{2}$ cells were either weakly depolarized or fired a few spikes in phase with $\mathrm{B} 4$ activity (Fig. $3 C$ ). Thirty-five $\mathrm{S}_{2}$ cells were fired with depolarizing current pulses, while recording from B4. In 17 of these cells, small 1-for-1 EPSPs wcrc rccordcd in $\mathrm{B} 4$, but these were usually too small to elicit firing. These data suggest that synaptic drive from individual $\mathrm{S}_{1}$ and $\mathrm{S}_{2}$ cells is too weak to account for patterned activity in B4. We cannot, however, eliminate the possibility that many $S_{1}$ or $S_{2}$ cells firing in tandem contribute to burst expression in $\mathrm{B} 4$.

\section{Inputs that initiate or modulate the patterns}

We were unable to find stimuli that initiated or modulated pattern 1. By contrast, we found that many stimuli could initiate pattern 2. Activity in B4 and B5 resembling that associated with spontaneous bursts of pattern 2 was elicited by electrical stimulation of most buccal nerves, but particularly the radular nerve (Fig. 4, $A, B_{1}$ ). A brief burst of high-frequency $(10 / \mathrm{sec})$ nerve stimulation usually elicited large, fast EPSPs and firing of cell B4, followed by a second burst of activity that was isomorphic with spontaneous bursts of pattern 2 (Fig. $4 A$ ). Pattern 2 was also elicited by sustained low-frequency $(2 / \mathrm{sec})$ nerve stimulation (e.g., Fig. 6C), which usually elicited 5-10 bursts of pattern 2 activity before the preparation would stop bursting in response to the stimulus. There was a fair degree of variability in the ability of a particular nerve to elicit pattern 2 and in the intensity or frequency of the pattern 2 bursts elicited by a nerve.

Pattern 2 was also driven by intracellular depolarization of many cells in the region between the $S_{2}$ cells and cells $B 1$ and B2 (Fig. 4 $B_{2}$ ). Except for B37 (described below, Fig. 19), these cells were not sufficiently characterized to allow identification. Another stimulus occasionally initiating a pattern 2 burst was strong activity of cell B4 itself (Fig. $4 B_{3}$ ). In 30 experiments, intracellular depolarizing current pulses were injected into cell B4 to test whether this stimulus could induce a subsequent burst in B4 resembling pattern 2. Twenty-seven of 113 attempts suc- 


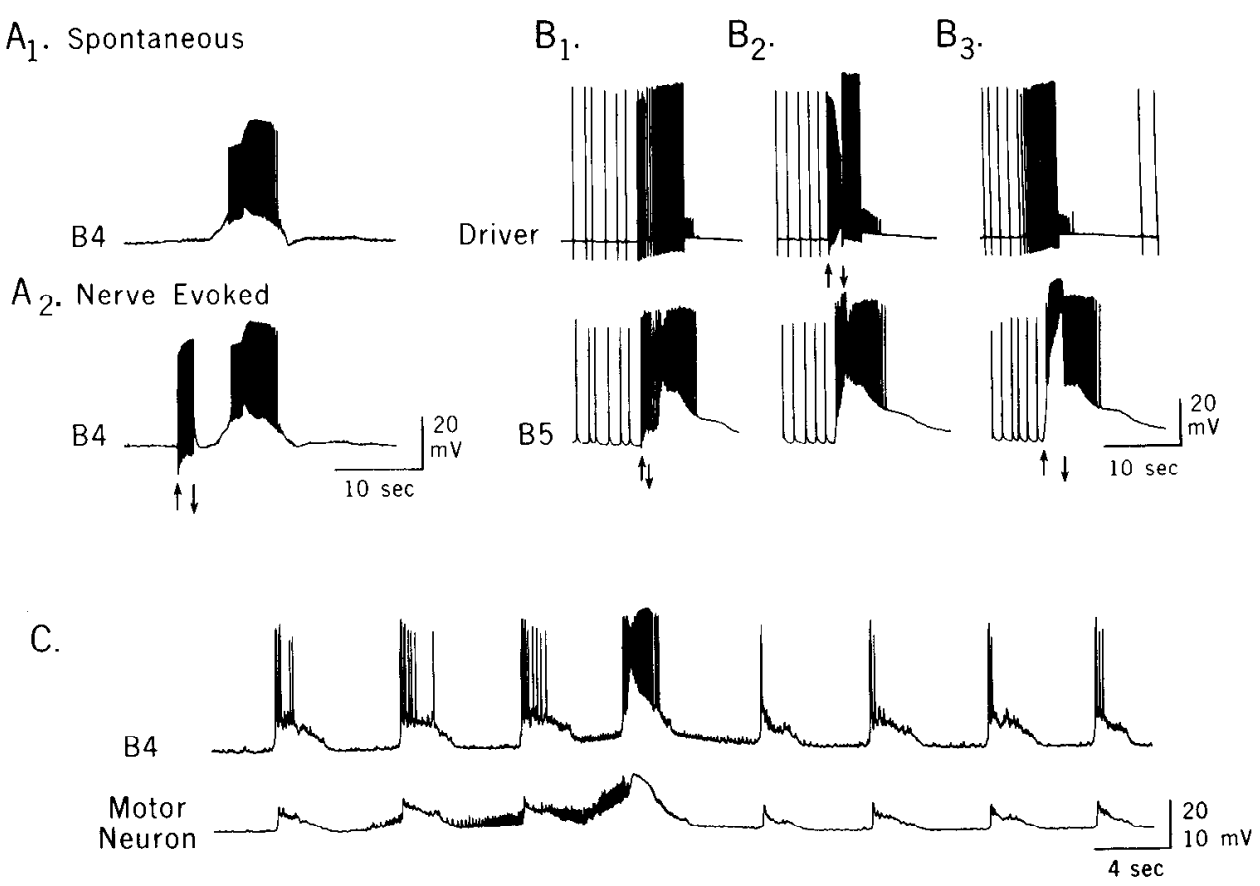

Figure 4. Stimuli that can initiate pattern 2. $A$, Spontaneous expression of pattern 2 in B4 $\left(A_{1}\right)$, and an identical pattern of firing in B4 initiated in the same cell by stimulation of the radular nerve at $10 / \mathrm{sec}\left(A_{2}\right)$. Onset and offset of the stimulation of the radular nerve in $A_{2}$ are indicated by arrows. The stimulus in $A_{2}$ elicits 2 bursts of spike activity in $\mathrm{B} 4$. The first coincides with the nerve stimulation; the second occurs after a delay and corresponds to pattern 2. $B$, Three stimuli that caused expression of pattern 2 . The traces show recordings from B5 and from an unidentified cell (Driver) in the region between the $S_{2}$ cells and $B 1$. This cell was active in phase with expression of pattern 2 and was able to drive initiation of the pattern. $B_{1}$, Pattern 2 as elicited by stimulation of the radular nerve. Onset and offset of nerve stimulation are shown by arrows. In this preparation, expression of pattern 2 closely followed initiation of the nerve stimulation (compare with pattern in $A_{2}$ ). $B_{2}$, Pattern 2 as elicited by firing the unidentified driver cell via an intracellular current pulse. Delivery of the pulse is indicated by the arrows. $B_{3}$, Pattern 2 as elicited by intracellular stimulation of B5. C, Expression of patterns 1 and 2 in B4 and in a cell from the motor neuron region of the ganglion. In this preparation, pattern 2 was expressed at the time that pattern 1 was expected to occur.

ceeded (e.g., Fig. $4 B_{3}$ ). These data suggest that $\mathrm{B} 4$ is a source of excitation to the initiator of pattern 2 , but its effect is weak or variable.

Finally, in one preparation showing spontaneous bursts of both patterns 1 and 2, bursts of activity associated with pattern 2 seemed to be closely linked with pattern 1 activity. Figure $4 C$ shows a simultaneous recording from $\mathrm{B} 4$ and from a cell in the motor neuron region. The motor neuron was depolarized in phase with expression of both patterns 1 and 2 in B4 and also showed a barrage of EPSPs preceding expression of pattern 2 in B4. Pattern 2 was initiated close to the time that pattern 1 was expected to occur, suggesting that cells driving pattern 1 may contribute to initiating pattern 2 . In this preparation, 8 successive spontaneous bursts of pattern 2 occurred close to the time that pattern 1 was expected. In all 8 bursts, the barrage of EPSPs in the motor neuron preceded expression of pattern 2 in B4. The data raise the possibility that the pattern generator for pattern 1 may drive that for pattern 2 but that this input is insufficient to cause activation of pattern 2 unless it summates with other inputs, such as that responsible for the barrage of EPSPs in the motor neuron.

\section{Newly identified cells driving patterned activity}

A number of characteristics would be expected of cells that initiate the 2 patterns of activity. For example, cells initiating pattern 1 should oscillate spontaneously at a rate similar to that of pattern 1 and be relatively unaffected by external input. Firing these cells should produce activity similar to that of pattern 1 , while hyperpolarizing them should remove the expression of pattern 1 in follower cells. Cells initiating pattern 2 should be active preceding bursts of spike activity in $\mathrm{B} 4$ and $\mathrm{B} 5$ and should be silent at other times. The cells should also receive convergent excitatory inputs from many cells in the ganglia including cell $\mathrm{B} 4$, and they should be activated by nerve stimulation. The cells should also be depolarized during pattern 1 activity. Firing the pattern 2 initiators should produce activity in B4 and B5 similar to that during spontaneous occurrences of pattern 2 , while hy perpolarizing them should eliminate expression of pattern 2 activity in follower cells such as B4.

We used cells B4 and B5 as monitors of patterns 1 and 2 and scarched the buccal ganglia for cells with the properties described above. We found an area of the buccal ganglia with a cluster of 5 cells (B31-B35) whose function seemed intimately related to initiating pattern 2 . The location of these cells, as well as 2 additional newly identified cells (B36 and B37), is shown in Figure 1. The cells were most commonly found just lateral to cell B1; occasionally they were just ventral to B1 or underneath it. These cells were usually readily visualized and were almost as large as the cells in the motor neuron region of the buccal ganglia.

Two of these cells, B31 and B32, have all the properties that are expected of cells initiating pattern 2 . Two additional cells, $\mathrm{B} 33$ and B34, are active along with B31 and B32, but they can be distinguished on the basis of a number of properties. In one preparation we recorded from all 4 cells ( 3 simultaneously), confirming that they are indeed different cells, rather than the 
A.
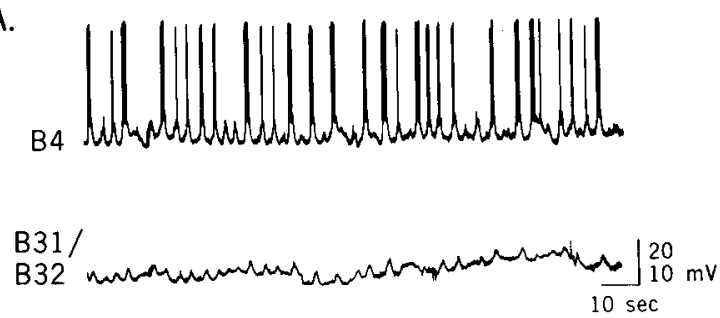

B.

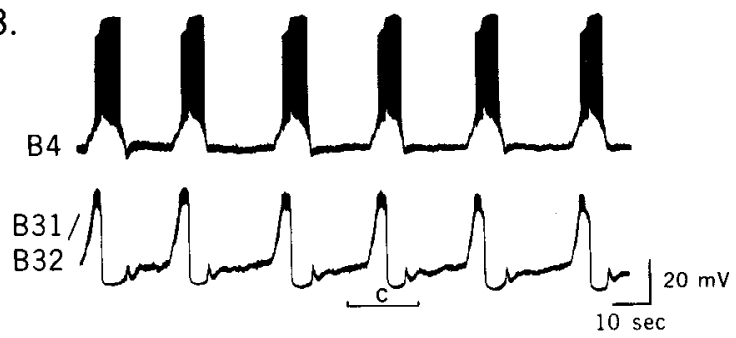

C.
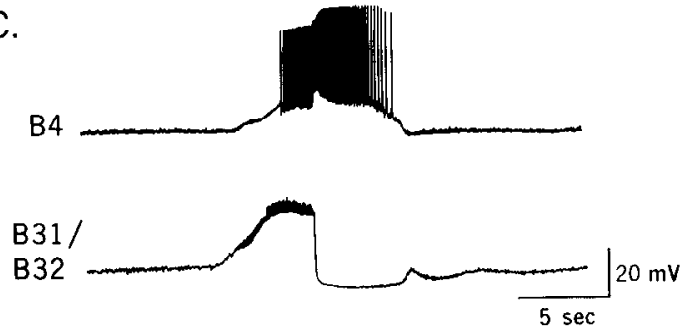

Figure 5. Spontaneous expression of patterns 1 and 2 , as recorded in B4 and in a B31/B32 cell. $A$, Expression of pattern 1 in B4 and B31/ B32. $B$, Expression of pattern 2 in $\mathrm{B} 4$ and $\mathrm{B} 31 / \mathrm{B} 32$ in a preparation in which pattern 1 was not expressed. $C$, Faster sweep speed of the burst of pattern 2 underlined in $B$ to show pattern 2 in greater detail.

same cell with variable properties in different preparations. Finally, cclls B35 and B36 had properties that differed considerably from those of B31-B34. It is possible that other cells in this cluster, or in other regions of the buccal ganglia, also contribute to initiating pattern 2 . In addition to cells B31-B36, one cell from the cluster between $B 1$ and the $S_{2}$ cells was identifiable, and this cell, B37, will also be described.

\section{Cells B31 and B32}

B31 and B32 lie adjacent to one another, have identical properties, and are electrotonically coupled with a coupling ratio of approximately 2:1 (see Fig. 13B). We refer to them interchangeably. The cells were found in 31 preparations.

Activity of B31/B32 during spontaneous bursts. Activity in $B 31$ and $B 32$ was associated with the expression of both patterns 1 and 2 in B4. During pattern 1 expression in B4, B31/B32 was weakly depolarized (Fig. $5 A$ ). This is consistent with the ability of input correlated with pattern 1 to summate with other inputs and initiate pattern 2 . In this experiment (Fig. $5 A$ ), spontaneous expression of pattern $2 \mathrm{did}$ not occur. In another preparation expressing only pattern $2, \mathrm{~B} 31 / \mathrm{B} 32$ was active preceding the activity of B4 (Fig. $5 B$ ). The activity of B31/B32 consists of a large depolarization starting before activity in $\mathrm{B} 4$ and continuing during the early phase of B4 firing (Fig. 5C). Small, spikelike depolarizations $<10 \mathrm{mV}$ in amplitude occur during the rising phase of the B31/B32 depolarization. We never observed overshooting action potentials in B31/B32, suggesting that their somata are inexcitable. The depolarization of $\mathrm{B} 31 / \mathrm{B} 32$ reaches its peak just preceding maximal spike activity in $\mathrm{B} 4$. A sharp repolarization of $\mathrm{B} 31 / \mathrm{B} 32$ then occurs, and the membrane potential of B31/B32 remains hyperpolarized during the remainder of the spike discharge in B4. In some preparations (e.g., Figs. $9 A, 11 A, 12 A$ ), there was virtually no overlap between the depolarization of B31/B32 and spike activity in B4. In these preparations activity in $\mathrm{B} 4$ corresponded with hyperpolarization of B31/B32. Some preparations (e.g., Fig. 7) displayed alternation of pattern 2 bursts in which depolarization of B31/B32 did and did not overlap with $\mathrm{B} 4$ firing.

Activity of B31/B32 during stimulus-elicited bursts. B31/B32 activity was examined during bursts of pattern 2 evoked in B4/ B5 by nerve stimulation (Fig. 6; compare the pattern with those in Figs. 4 and 5). During bursts evoked by low-frequency stimulation of the csophageal nerve (Fig. 6A) and by high- and lowfrequency stimulation of the radular nerves (Fig. 6, B, C), B31/ B32 showed the same depolarization-repolarization activity pattern as during spontaneous pattern 2 activity (Fig. 5, $B, C$ ). The depolarization of $\mathrm{B} 31 / \mathrm{B} 32$ corresponded to the early phase of activity in cell $\mathrm{B} 4$, and the repolarization of $\mathrm{B} 31 / \mathrm{B} 32$ occurred

\section{A. Esophageal Nerve}

B4

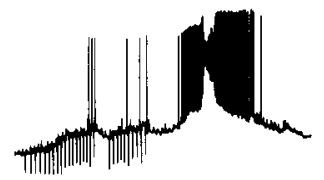

B5
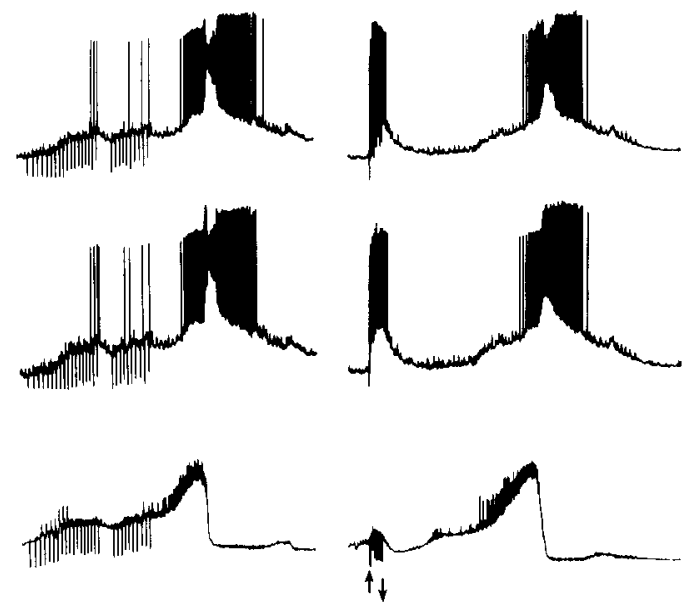

B. Radular Nerve (high frequency)

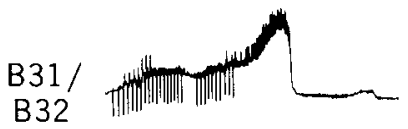

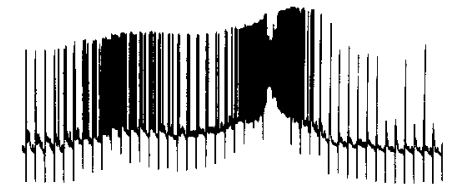

C. Radular Nerve

(low frequency)
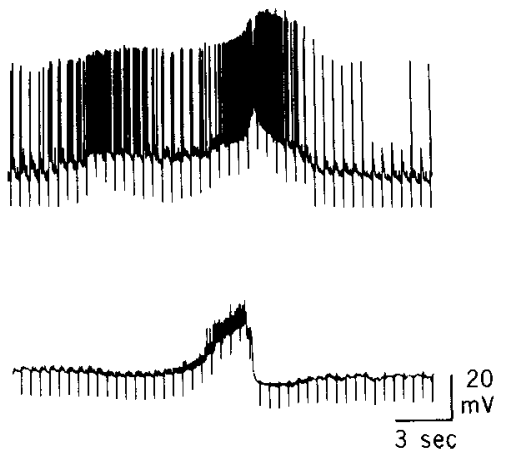

Figure 6. Simultaneous expression of pattern 2 in cells B4 and B5, and in B31/ B32. A, Activity initiated by stimulation of the anterior division of the esophageal nerve. $B$, Activity initiated by brief $10 / \mathrm{sec}$ stimulation of the radular nerve. Onset and offset of the stimulus arc indicatcd by arrows. This stimulus elicits 2 bursts of activity in B4. The earlier burst occurs during stimulation of the radular nerve, presumably reflecting direct synaptic input to $B 4$ from cells with axons in the nerve. The later burst of activity follows depolarization of $\mathrm{B} 31 / \mathrm{B} 32$, presumably representing expression of pattern 2. $C$, Activity initiated by low-frequency stimulation of the radular nerve. 


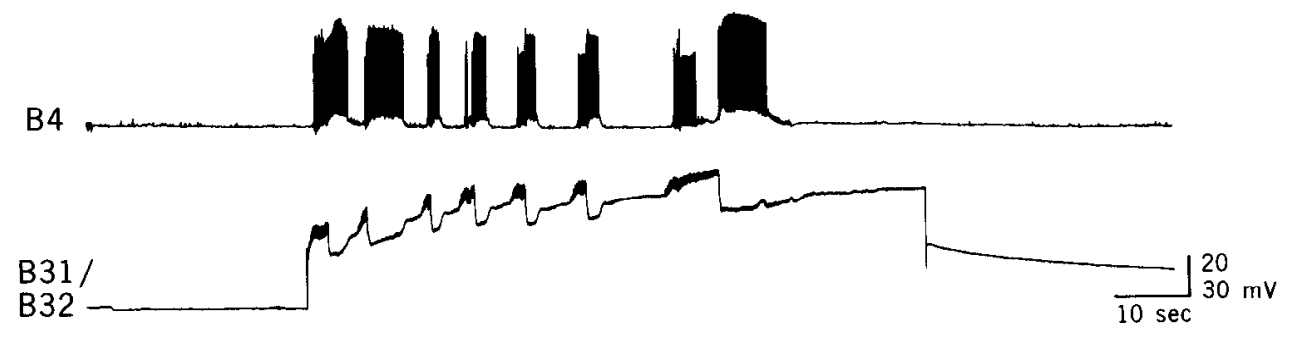

Figure 7. Sustained depolarization of B31/B32 elicits rhythmic bursts of activity in itself and in B4. The number of spikes per B4 burst and the waveform of the depolarization underlying each burst were highly variable despite the constant stimulus to B31/B32. In this preparation, B31/B32 was impaled with a single microelectrode. Sustained stimulation produced polarization of the electrode, leading to a gradual upward drift in the recording of B31/B32 activity. This was not observed in other experiments when separate electrodes were used for stimulation and recording from B31/B32.

during the most intense spike activity in $\mathrm{B} 4$. As in the recordings shown in Figure 4, high-frequency stimulation of the radular nerve (Fig. $6 B$ ) evoked a burst of spike activity in B4 synchronous with the nerve stimulation, followed by a second burst that was similar to spontaneous bursts of pattern 2 .

Effects of intracellular stimulation of $B 31 / B 32$. In quiescent preparations, sustained depolarization of $B 31 / B 32$ led to repetitive cycles of activity in both B31/B32 and in B4 (Fig. 7). The oscillations of $\mathrm{B} 4$ were phase-locked to those of $\mathrm{B} 31 / \mathrm{B} 32$. The number of cycles elicited by a sustained depolarizing stimulus to B31/B32 varied. In some experiments, only 2-3 cycles could be elicited, while in others cyclic activity was maintained throughout the depolarization. One preparation showed 31 cycles during a 5 min depolarization.

In one preparation we were able to compare the activities of B4 and B31/B32 directly when pattern 2 occurred spontaneously (Fig. $8 A$ ), when elicited by nerve stimulation (Fig. $8 B$ ), and when produced by intracellular depolarization of B31/B32 (Fig. 8C). These were remarkably similar, confirming that all 3 are likely to represent activation of the same pattern generator.

Effects of hyperpolarization of B31/B32. We did not systematically examine the effects of hyperpolarizing B31/B32 on spontaneous occurrences of pattern 2 since these were highly irregular. Thus, if pattern 2 ceased during hyperpolarization of B31/ B32, we could not be certain whether this was due to the hyperpolarization or was spontaneous. We did, however, take advantage of the fact that pattern 2 activity in B4 (and in B31/ B32) could be reliably elicited by nerve stimulation. Thus, to determine whether B31/B32 or closely coupled cells are nec- essary for burst initiation in B4, we hyperpolarized B31/B32 while electrical stimulation was delivered to a peripheral nerve. In one preparation, hyperpolarization of B31/B32 during stimulation of the radular nerve reliably blocked expression of pattern 2 (Fig. 9), while in another preparation hyperpolarization blocked the depolarization-repolarization sequence usually seen in B31/B32 but did not eliminate expression of pattern 2 in B4. Figure 9 shows an example of hyperpolarizing B31/B32 during stimulation of the radular nerve in the preparation in which this procedure blocked pattern 2 bursts in B4. Note that the early component of B4 activity that is synchronous with stimulation of the nerve is unaffected by hyperpolarization of $B 31 / B 32$. Note also that the input to $\mathrm{B} 31 / \mathrm{B} 32$ is reduced by the hyperpolarization. These data indicate that cells B31/B32 are intimately involved in generating burst 2 , but it is likely that other cells can also initiate this pattern. One potential source for such additional input is the contralateral B31/B32 cells (unpublished observations). Since we hyperpolarized only a single ipsilateral B31/B32, it is possible that activity of the contralateral cells could override the ipsilateral block.

Coupling of B31/B32 to B4. Further evidence supporting the hypothesis that cells B31/B32 are involved in initiating pattern 2 would be provided by demonstrating that activation of cell B4 can weakly excite these cells since B4 can sometimes initiate pattern 2 (Fig. $4 B_{3}$ ). We found that intracellular firing of $\mathrm{B} 4$ excites B31/B32 (Fig. 10A). Furthermore, B31/B32 and B4 are weakly electrically coupled (Fig. 10B). Hypcrpolarizing current pulses injected into either cell could be recorded in the other. Coupling, however, was not detected in every preparation.
Figure 8 . Identity of the form of pattern 2 as expressed in B4 and B31/B32 in the same preparation when pattern 2 was caused by different events. $A$, Spontaneous occurrence of pattern $2 . B$, Pattern 2 elicited by $10 / \mathrm{sec}$ stimulation of the radular nerve. $C$, Pattern 2 elicited by intracellular stimulation of B31/ B32. Arrows show onset and offset of the stimulation of the radular nerve and of the depolarizing pulse in B31/B32.

\section{A. Spontaneous}

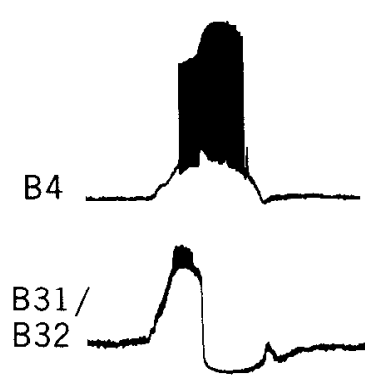

B. Evoked by Radular Nerve

C. Evoked by Intracellular Pulse
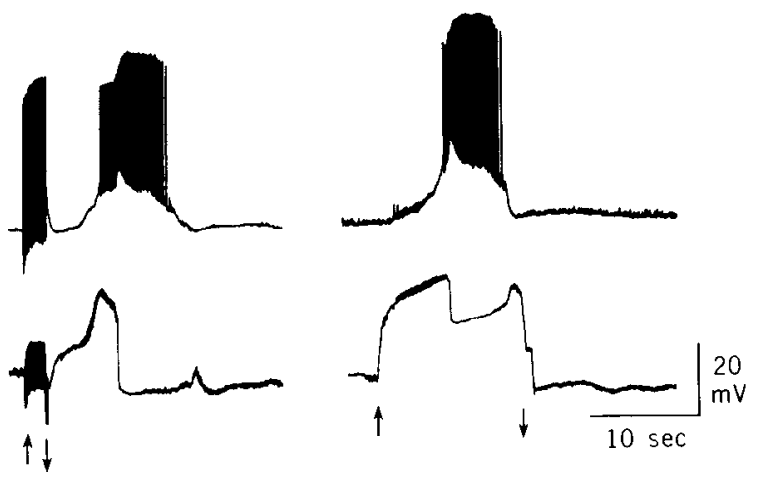
A. Control

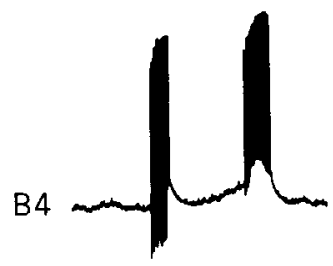

B. B31/B32

Hyperpolarized
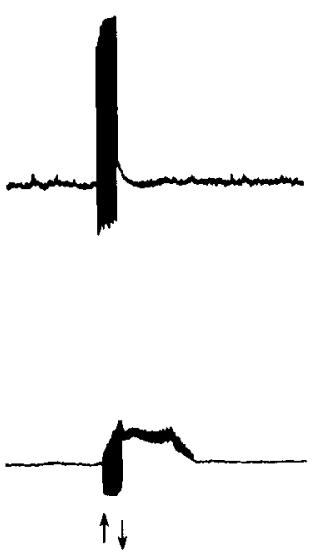

C. Control
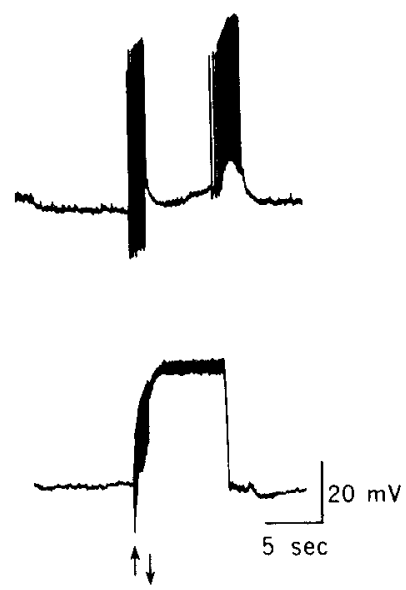

Figure 9. Hyperpolarization of B31/ B32 blocks expression of pattern 2 in B4. A, Two bursts of spikes in B4 were initiated by stimulation of the radular nerve. The second burst corresponded to pattern 2 and occurred in phase with termination of depolarization of B31/ B32. $B, \mathrm{~B} 31 / \mathrm{B} 32$ was hyperpolarized by approximately $30 \mathrm{mV}$. Nerve stimulation no longer initiated the late pattern 2 burst in B4, but the early input was unchanged. $C$, After the hyperpolarization was removed, stimulation of the nerve once again initiated pattern 2. Onset and offset of stimuli to the radular nerves are indicated by arrows.
Nature of the activity in B31/B32. The firing pattern of B31/ $B 32$ is characterized by an initial depolarizing phase associated with spikelike potentials, followed by a rather sharp repolarizing phase. At least part of this pattern appears to be triggered in an all-or-none fashion by some critical level of depolarization of B31/B32. Figure $11 B$ illustrates a fairly dramatic example, where a brief depolarization delivered to B31/B32 was sufficient to initiate a complete pattern of activity (Fig. $11 B$ ) that was essentially the same as that occurring spontaneously (Fig. 11A). Thus, a regenerative mechanism appears to be either intrinsic to cells B31/B32 or a property of a network in which the B31/ $\mathrm{B} 32$ cells are an element. Usually, the regenerative depolarization in $\mathrm{B} 31 / \mathrm{B} 32$ was followed by the sharp repolarization and activity in $\mathrm{B} 4$. However, in 2 preparations, regenerative bursts of B31/B32 occasionally were seen without subsequent sharp repolarization and $\mathrm{B} 4$ activity. Figure $12 \mathrm{~A}$ shows an example of the typical spontaneous pattern 2 activity in both cells, while Figure $12 B$ shows a recording from the same preparation in which both the sharp hyperpolarization in B31/B32 and the burst in B4 failed to occur. These data suggest that drive to B4 and hyperpolarization of $\mathrm{B} 31 / \mathrm{B} 32$ are due to activation of an unidentified cell that is in turn activated by $\mathrm{B} 31 / \mathrm{B} 32$ and feeds back onto $\mathrm{B} 31 / \mathrm{B} 32$ to inhibit it. A failure to activate this presumed cell may account for the data in Figure $12 B$.

\section{Cell B33}

B33 is adjacent to cells B31 and B32 (Fig. 1) and is also able to initiate pattern 2 . The properties and activity pattern of B33 are similar to those of B31/B32 (Fig. 13A). However, in addition to exhibiting the small spikelike potentials seen in B31/B32, B33 also displayed conventional action potentials with amplitudes of 50-60 mV (Fig. 13A). Hyperpolarizing current pulses injected into B33 produced voltage changes in B31 and B32 (Fig. 13B), indicating that these cells are coupled to one another. The coupling ratio was about 2:1. Action potentials in B33 also produced voltage changes in B31 and B32 (Fig. 13C). Cell B33 was identified in 10 preparations.

Electrotonic propagation of action potentials from cell B33 to $\mathrm{B} 31 / \mathrm{B} 32$ raises the possibility that the small spikelike potentials in B31/B32 are electrotonic potentials from full-size action potentials in B33. Overshooting action potentials in B33 do indeed cause coupling potentials in B31 and B32 (Fig. 13C), but these are a minor component of the spikelike activity. There are a number of discrete spikelike potentials synchronous in all 3 cells, but the activity pattern is too complex to resolve how many such events occur. Thus, coupling between B33 and B31/ B32 cannot fully account for the spikelike potentials in B31/ B32. The spikelike potentials in B31/B32 could be generated in

A.
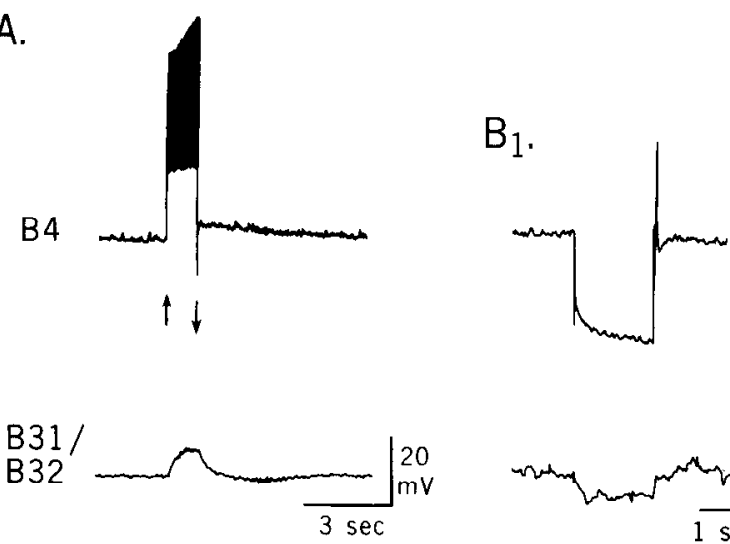

$\mathrm{B}_{2}$.
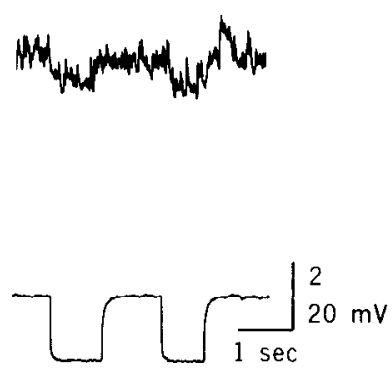

Figure 10. Connection between cells B4 and B31/B32. A, Intracellular depolarization of $B 4$ to fire a burst of spikes elicited depolarization of B31/B32. Arrows indicate onset and termination of the current pulse. $B$, Weak electrical coupling between cells B4 and B31/B32. Injecting hyperpolarizing current into one cell produced an electrotonic potential in the other. 


\section{A. Spontaneous}

Figure 11. Ability of B31/B32 to produce a regenerative, sustained depolarization in response to a brief depolarizing stimulus. $A$, Spontaneous activity resembling pattern 2 in cells $B 4$ and B31/B32. $B$, Initiation of a nearly identical sequence of events in $\mathrm{B} 31 / \mathrm{B} 32$ and a burst in $\mathrm{B} 4$ was produced by a brief depolarization of B31/B32 (onset and offset of depolarization indicated by $a r$ rows). Note that B31/B32 remains depolarized for some time after the current pulse to $\mathrm{B} 31 / \mathrm{B} 32$ is terminated.

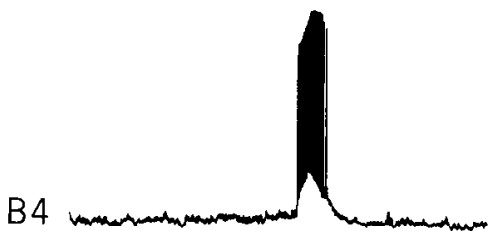

B. Evoked
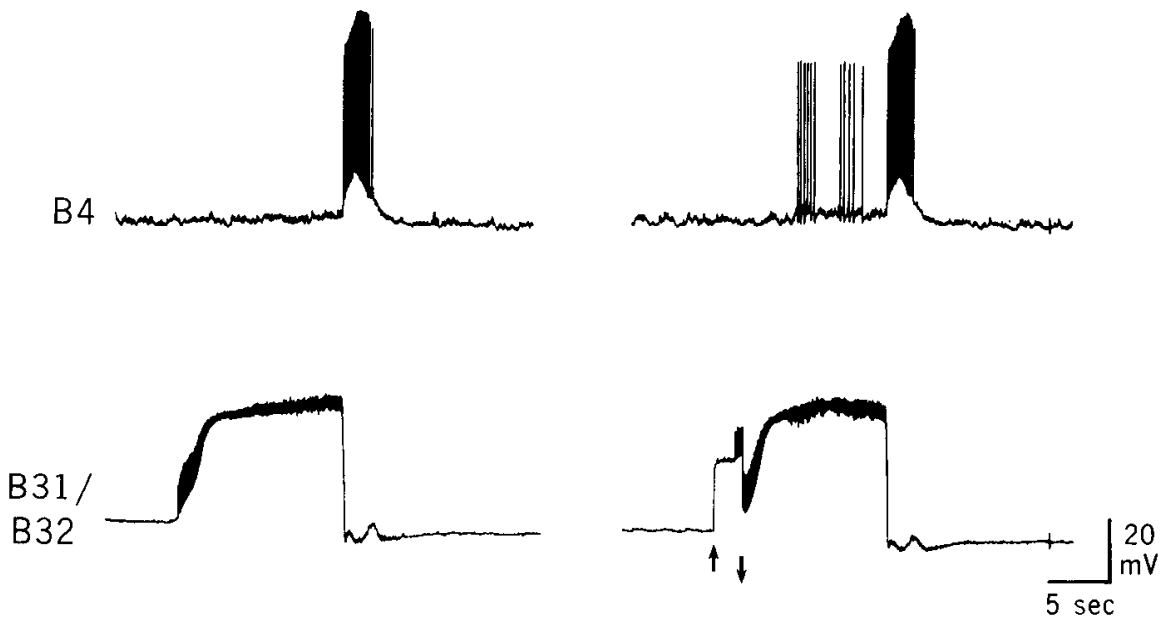

excitable regions of $\mathrm{B} 31 / \mathrm{B} 32$ or may come from unidentified cells like B33 that are also coupled to B31/B32.

Depolarization of B33 could elicit pattern 2, provided that the depolarization was sufficient to elicit the depolarizationrepolarization sequence in cells $\mathrm{B} 31 / \mathrm{B} 32$. In the experiment shown in Figure 14, B33 was depolarized with an intracellular constant current pulse every $50 \mathrm{sec}$. Only on every sixth depolarization was B33 capable of eliciting activity in B4. B33 consistently depolarized B31/B32, but it did not always produce patterned activity in B31/B32. When patterned activity in B31/ B32 was absent, B4 did not fire. The reduced effectiveness of B33 in initiating pattern 2 following a burst in B4 can be explained by a number of mechanisms. Most likely is the presence of a sustained, slowly decaying hyperpolarization of B31/B32 after pattern 2 (Fig. 14). The first 2 current injections of B33 after a burst in $\mathrm{B} 4$ occurred during the sustained hyperpolarization of B31/B32 and produced relatively small depolarizations of cells B33 and B31/B32, no spiking in B33, and no activity in $\mathrm{B} 4$. This presumably reflects the activity of a slow increased conductance mechanism, accounting for the B31/B32 hyperpolarization, which shunts the current injected into B33 and leads to a functional reduction in coupling between $\mathrm{B} 31 /$ B32 and B33. After the hyperpolarization of B31/B32 decayed, the constant-current pulse to B33 elicited spikes in B33, and larger potentials in B31/B32, but still failed to elicit pattern 2 . In this preparation, the recovery period was greater than $5 \mathrm{~min}$.

\section{Cell B34}

B34 is also adjacent to B31 and B32 (Fig. 1) and has a similar pattern of activity. It can be distinguished from the previously described cells in 2 ways. First, the pattern of depolarization and repolarization is of smaller amplitude (Fig. 15A). Second, depolarization of the cell does not induce patterned activity. Moreover, the cell is only weakly coupled to cells B31-B33 (Fig. $15 B)$. Cell B34 was identified in 5 experiments.

\section{Cell B35}

B35 is adjacent to cells B31-B34 (Fig. 1). Like B31/B32, B35 has a prominent regenerative capability. However, B35 differs from $\mathrm{B} 31 / \mathrm{B} 32$ in that it displays conventional action potentials and that patterned activity in B4 was often seen in the absence of $\mathrm{B} 35$ activity. Cell B35 differs from B33 in that it is only weakly coupled to B31/B32 and often fires both before and after the B4 burst. Also, firing B35 depolarizes cell B4 even when $\mathrm{B} 31 / \mathrm{B} 32$ is not activated. B35 is also characterized by $10-30$
Figure 12. Spontaneous activity in B4 and $\mathrm{B} 31 / \mathrm{B} 32$ in a preparation in which the regenerative burst in $\mathrm{B} 31 / \mathrm{B} 32$ sometimes failed to elicit the sharp repolarization in $\mathrm{B} 31 / \mathrm{B} 32$ and the maximal drive in B4. A, Example of a spontaneous burst of pattern 2 in both cells. In this example, the depolarization of B31/B32 was followed by the typical sharp repolarization. $B$, Spontaneous depolarization of B31/B32 that was not followed by the sharp repolarization in B31/B32. When the sharp repolarization was absent, so was the spike burst in B4. The 2 traces shown occurred within $1 \mathrm{~min}$ of one another.
A.
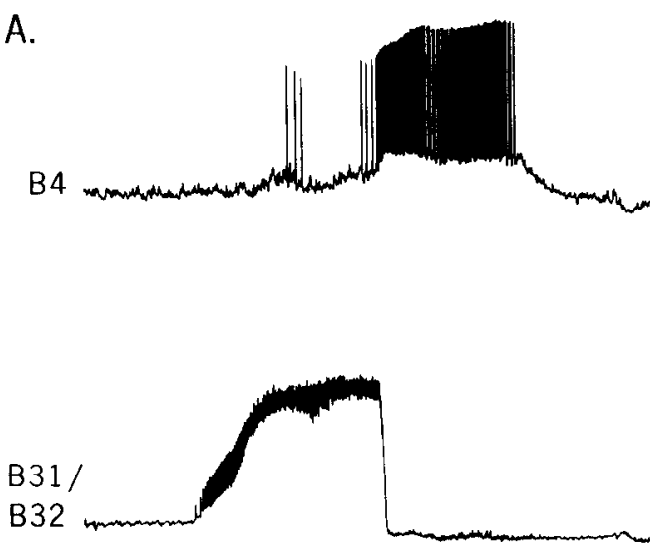

B.

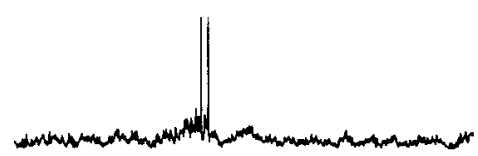



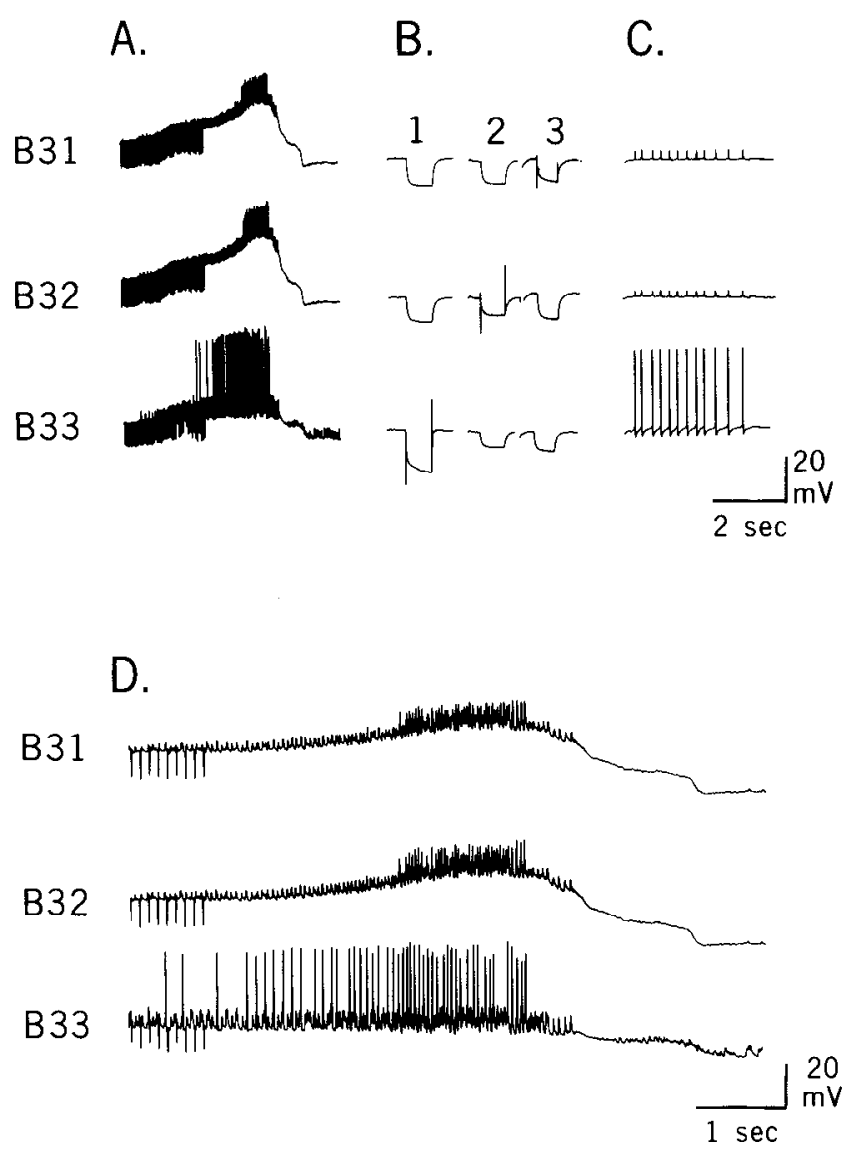

Figure 13. Activity of B33. A, Activity pattern in cells B31-B33 elicited by stimulating the esophageal nerve. While the activity patterns in all 3 cells are similar, B33 displays conventional action potentials that do not occur in cells B31 and B32. B, Electrical coupling among B31, B32, and $\mathrm{B} 33$, as shown by injecting hyperpolarizing current pulses into each and recording changes in potential from the other cells. $B_{1}$, Current injected into $\mathrm{B} 33 ; B_{2}$, current injected into $\mathrm{B} 32 ; B_{3}$, current injected into B31. $C$, Small spikelike potentials are produced in B31 and B32 as a result of firing spikes in B33 with a sustained intracellular depolarizing current pulse. These spikelike events are presumably due to the electrical coupling among the cells. $D$, Faster sweep of recordings made after stimulation of the radular nerve. Coupling potentials from $\mathrm{B} 33$ represent a minor component of the spikelike potentials seen in B31 and B32. sec bursts of spiking that ride on a slow depolarization of the cell (e.g., Fig. 16A). B35 was identified in 7 experiments.

The firing pattern of B35 is illustrated in Figure 16. Spontaneous bursts in B35 are associated with slow depolarization and repolarization of $\mathrm{B} 35$, depolarization of $\mathrm{B} 31 / \mathrm{B} 32$, and depolarization and firing of $\mathrm{B} 4$ (Fig. 16A). In 4 preparations, firing $\mathrm{B} 35$ with brief intracellular current pulses repeatedly produced depolarization of B31/B32 and of B4 resembling that seen in Figure $16 \mathrm{~A}$ but did not elicit pattern 2 activity (not shown). In 5 preparations, activity of B35 during bursts of pattern 2 was similar to that illustrated in Figure $16 \mathrm{~B}$. B35 was active in phase with B31/B32 and was hyperpolarized during maximal activity in B4. However, unlike cells B31-B34, which were inactive after the pattern 2 spike burst in B4, B35 also fired a second time following the B4 burst. In 3 preparations, intracellular stimulation of B35 occasionally was able to elicit pattern 2 (Fig. 16C). In 3 preparations, hyperpolarization of B35 to prevent its firing did not block expression of pattern 2 elicited via nerve stimulation or by depolarization of $\mathrm{B} 31 / \mathrm{B} 32$, indicating that $\mathrm{B} 35$ activity is not necessary for expression of pattern 2 .

A striking feature of cell B35 was observed in 5 preparations. Brief (1-2 sec) depolarization induced massive activity that long outlasted the depolarization (Fig. 17A). Moreover, if B35 was hyperpolarized after onset of activity, thc activity could be turncd off (Fig. $17 B$ ). Note that during the postburst hyperpolarization there is no obvious synaptic drive in B35. B35 resembles B31/ $\mathrm{B} 32$ in that a regenerative mechanism amplifies the initial excitation to the cell. Activity in B4 and B31/B32 during regenerative bursts initiated by brief depolarization of $\mathrm{B} 35$ was similar to that illustrated in Figure $16 \mathrm{~A}$.

\section{Cell B36}

B36 lies adjacent to cells B31-B35 (Fig. 1) but is easily distinguished from them. B36 differs from B31/B32, B33, and B35 in that firing the cell via intracellular current pulses elicits little or no excitation of B31/B32 or of B4 (Fig. 18A). Like cells B31/ $\mathrm{B} 32$ and $\mathrm{B} 35, \mathrm{~B} 36$ has a powerful regenerative ability (Fig. 18A). However, during the regenerative burst, B36 more closely resembles B31/B32 than B35 in that as the cell becomes maximally depolarized the amplitude of the action potentials is great-
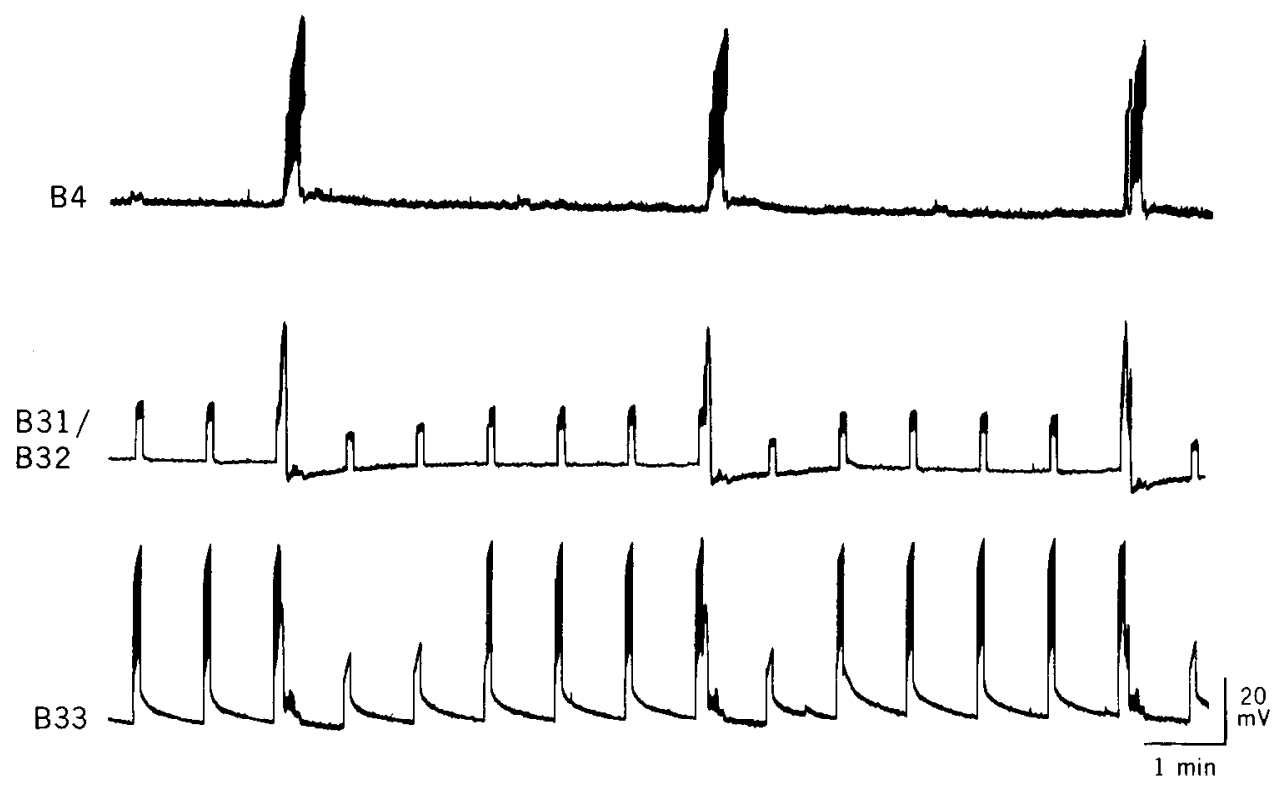

Figure 14. Effects of intracellular injection of a constant depolarizing current pulse into B33 every $50 \mathrm{sec}$. After a spike burst in B4 was generated, the next 5 current pulses delivered to B33 failed to elicit a spike burst in B4. The failure of B33 to activate B4 is associated with a failure of the depolarizing current in B33 to fire spikes in B33 and a long-lasting hyperpolarization in B31/ B32. Even after the hyperpolarization in B31/B32 recovered and spikes were again elicited in B33, a full-fledged depolarization-repolarization cycle in B31/B32 and a burst of spikes in B4 were not produced. A burst in B4 was again produced when activation of $B 33$ was capable of eliciting a depolarization-repolarization cycle in B31/B32. 

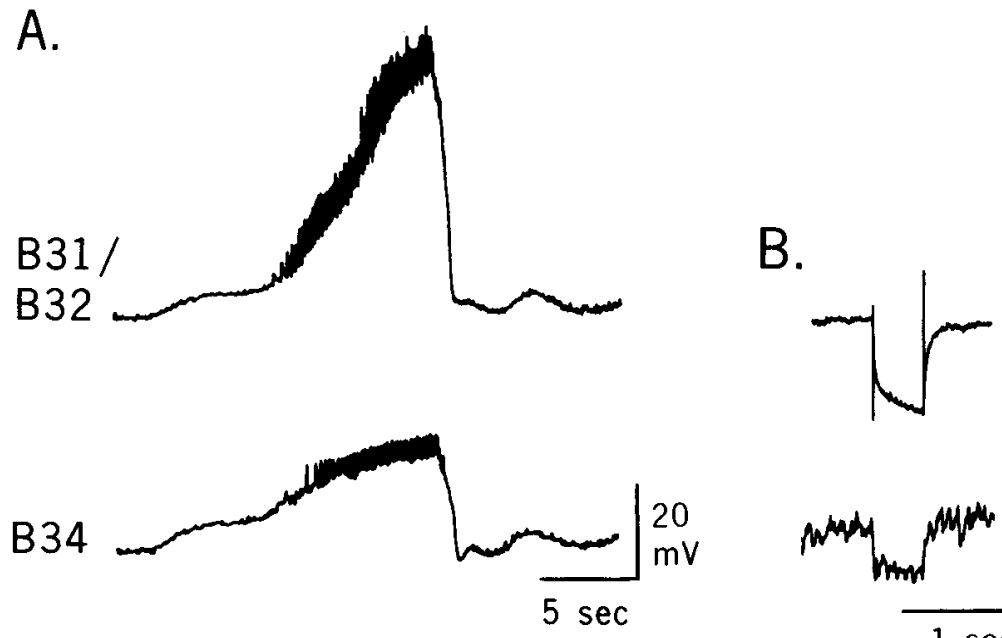

gure 15. Properties of B34. A, Activity patterns of cells B31/B32 and B34 during a spontaneous occurrence of pattern 2. Patterns are similar in both cells, but the amplitude of the depolarization-repolarization sequence is smaller in B34. $B$, Weak electrical coupling between B31/B32 and B34. Current was injected into B31/B32. The coupling ratio was approximately $20: 1$.

ly reduced. A striking difference between B36 and B31-B35 is that their firing patterns during expression of pattern 2 are exactly opposite. B36 is hyperpolarized during the maximal depolarization of $\mathrm{B} 31 / \mathrm{B} 32$ and is depolarized during the sharp repolarizing phase of B31/B32 activity (Fig. 18B). Cell B36 was identified in 8 preparations.

\section{Cell B37}

Cell B37 is located medial to cell B1 (Fig. 1), among a cluster of cells that could activate patterned activity in B4 (e.g., Fig. $4 B_{2}$ ). To date, B37 is the only cell in the cluster that has been characterized sufficiently for repeated identification. The ecll differs from others in the cluster in that it is not active during pattern 2 initiated by either stimulation of peripheral nerves or by depolarization of B31/B32 (for an example of a cell that is, see Fig. $4 B$ ), it does not monosynaptically excite B4, and it has no spontaneous oscillatory activity. Depolarization of the cell, however, initiates pattern 2 activity. Cell B37 was identified in 4 preparations.

Intracellular depolarization of B37 sufficient to generate a high-frequency burst of spikes led to a marked depolarization of B31/B32 and a burst of spikes in B4 resembling pattern 2
(Fig. 19A $A_{1}$. To test whether activation of pattern 2 in $\mathrm{B} 4$ was due to activation of $\mathrm{B} 31 / \mathrm{B} 32$, we hyperpolarized $\mathrm{B} 31 / \mathrm{B} 32$ while depolarizing B37 (Fig. 19A2). Pattern 2 was not elicited, although some excitation of B4 was still evident. This is shown more clearly in Figure 19B. Note also that B37 produced little underlying synaptic input in B31/B32 when that cell was hyperpolarized.

\section{Discussion}

\section{Patterns of neural activity}

We have identified 2 patterns of neural activity in the buccal ganglia of Aplysia. The 2 patterns can be distinguished on the basis of several features.

Pattern 1 . This pattern occurred spontaneously at a relatively high frequency. It was associated with excitation that was usually sufficient to induce bursts of action potentials in cells B4 and B5 and in other motor neurons, and weaker excitation of the $S_{1}$ and $S_{2}$ cells, of some other motor neurons, and of cells B31/ B32. Inhibition of other motor neurons and of cells B1 and B2 were also associated with pattern 1.

Pattern 2. This pattern was associated with strong excitation of B4 and of many motor neurons, excitation of the $S_{1}$ and $S_{2}$
Figure 16. Properties of B35. A, Spontaneous activity recorded from B35, $\mathrm{B} 31 / \mathrm{B} 32$, and B4. A burst of spikes in $\mathrm{B} 35$ is correlated with depolarization of B31/B32, as well as depolarization and moderate increase in firing of $B 4$. $B$. Expression of pattern 2 in B35. B35 fires during the depolarization of $\mathrm{B} 31 /$ B32, and, like B31/B32, it repolarizes when B4 fires maximally. After the spike burst in B4, a second burst occurs in B35. This is unlike B31/B32, which generally does not undergo a second depolarization-repolarization sequence following activity in B4. $C$, Intracellular depolarization of B35 is capable of driving $\mathrm{B} 31 / \mathrm{B} 32$ and eliciting pattern 2-like activity in B4. The cell was maintained in a hyperpolarized state and was then depolarized. Onset and offset of the depolarization is indicated by arrows, as is return to a hyperpolarized state.
A.

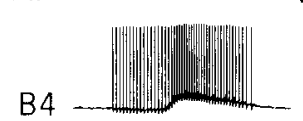

B.
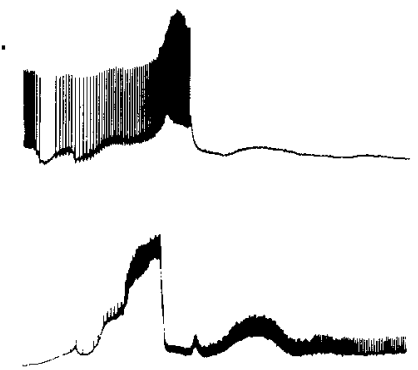

B31/

B32
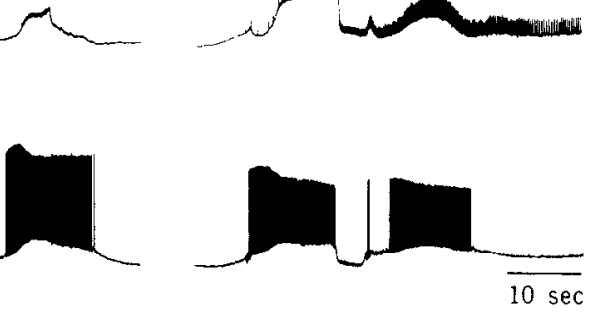

C.

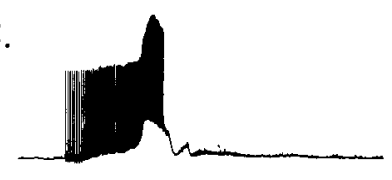


A.

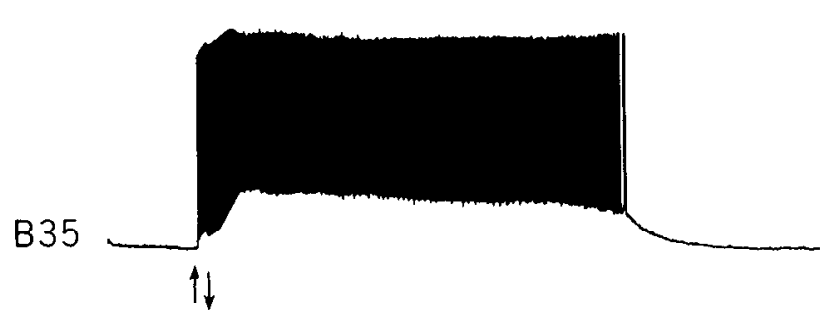

B.

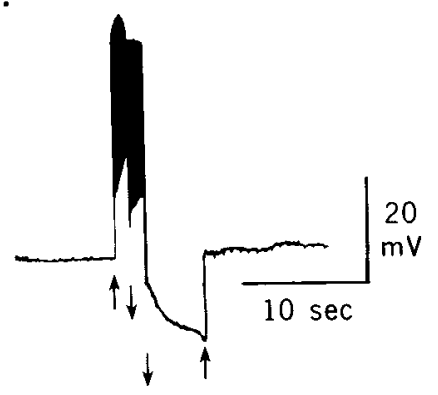

Figure 17. Regenerative properties of B35. $A$, Initiation of activity by a brief intracellular depolarization of B35. Onset and offset of the depolarization are indicated by arrows. $R$, A burst of activity in B35 was initiated by a brief intracellular depolarization. The burst was terminated by injecting a hyperpolarizing current into $\mathrm{B} 35$. Onset and offset of the depolarization and the hyperpolarization are indicated by arrows. cells, and inhibition of B1 and B2. Perhaps the clearest distinguishing feature of pattern 2 is the presence of a characteristic depolarization in cells $\mathrm{B} 31 / \mathrm{B} 32$ preceding activation of $\mathrm{B} 4$, followed by repolarization of B31/B32. Pattern 2 occasionally occurred spontaneously but was more commonly elicited by electrical stimulation of various buccal nerves or by depolarization of individual cells such as B4, newly identified cells including B31/B32, and a number of unidentified cells.

\section{Pattern initiator neurons}

We have found a group of cells that appear to contribute to initiating pattern 2. Of particular importance are the B31/B32 cells. These are activated by stimuli that induce pattern 2 in $\mathrm{B} 4 / \mathrm{B} 5$ and are active preceding spontaneous expression of pattern 2. Intracellular depolarization of the cells can produce pattern 2, while hyperpolarization of B31/B32 can block expression of pattern 2. It is possible the effects of B31/B32 are partly mediated via electrical and chemical connections to other cells that have yet to be identified. For example, hyperpolarization of B31/B32 was not always effective in preventing expression of pattern 2. The existence of other circuit elements is also suggested by the finding that in cases in which activation of a regenerative response in $\mathrm{B} 31 / \mathrm{B} 32$ failed to initiate pattern 2, the sharp repolarization that corresponded to the major phase of activity in B4 was also absent (e.g., Fig. 12).

\section{Unusual properties of newly identified cells}

Some of the cells we have identified display properties that are unique or unusual in the nervous system of Aplysia. Some of these properties have previously been observed in neurons with putative pattern-generator or command functions in the feeding motor systems of other gastropods.

Regenerative properties. In cells B31, B32, B35, and B36 brief depolarization induces a positive-feedback mechanism that produces a larger depolarization or a burst of activity continuing well after the depolarization is terminated. Similar cells have been described in the feeding motor systems of Pleurobranchaea (Gillette et al., 1980; Croll et al., 1985) and Lymnaea (Rose and Benjamin, 1981; Elliot and Benjamin, 1985; McCrohan, 1985), as well as in pattern-generating elements in crustacea (Benson and Cooke, 1984). Cell C2 in the cerebral ganglion of Aplysia also has similar properties (Weiss et al., 1986b). The regenerative ability could be due to endogenous properties of the cells or to a positive-feedback network in which other cells are activated. The function of the regenerative excitation may be to trigger a particular feeding movement so that it occurs in an allor-none fashion.

Lack of ability to sustain action potentials. Cells B31, B32, and B34 are the first neurons identified in the Aplysia nervous system whose somata seem to lack the ability to sustain fullsize, overshooting action potentials. Although nonspiking neurons have been found in vertebrates (Dowling, 1970) and in arthropods (Pearson and Fourtner, 1975), such cells are rare in gastropod molluscs (but see Arshavsky et al., 1985).

A number of observations indicate that the lack of ability to sustain action potentials is not due to damage. First, at least one B31/B32 was found in over 30 preparations. Second, the properties of these cells were very distinctive, and the cells were
A.

B31/ B32

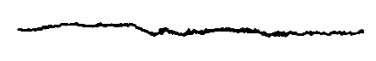

B.

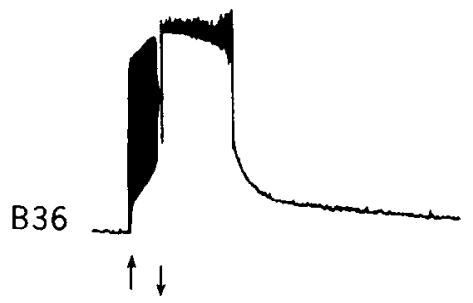

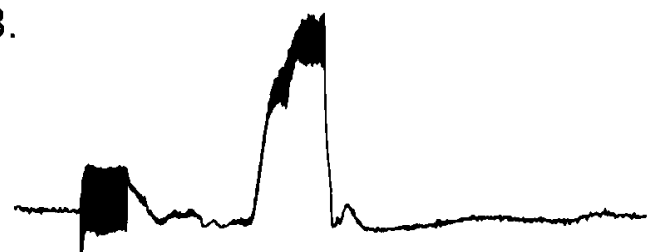

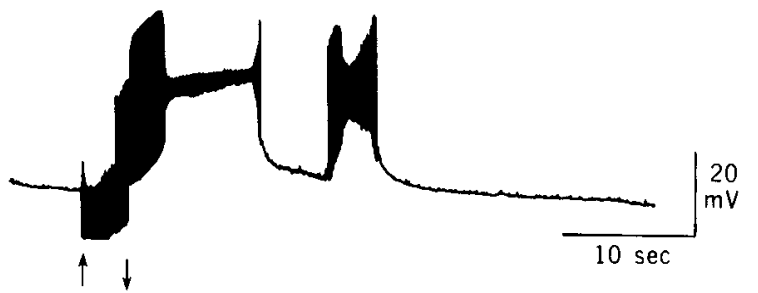

Figure 18. Properties of B36. A, Brief intracellular depolarization of B36 elicits a regenerative response but does not excite B31/B32. Onset and termination of the depolarization are indicated by arrows. $B$, Pattern of B36 activity during pattern 2 elicited by radular nerve stimulation. (Onset and offset of nerve stimulation are indicated.) B36 is strongly activated by stimulation of the nerve. Activity of B36 continues until B31/B32 begins to depolarize, and then activity in B36 abruptly ceases. B36 is then silent throughout the depolarization of B31/B32 but is again active when B31/B32 hyperpolarizes. 


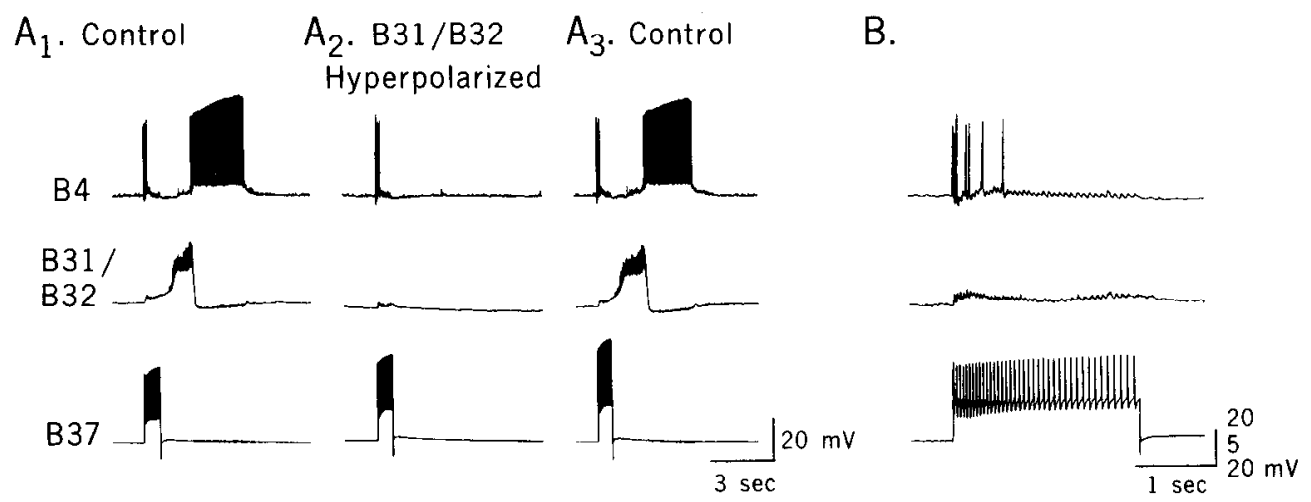

Figure 19. B37 elicits activity in B4 via its effects on B31/B32. A, Burst of spikes in B37 is elicited by an intracellular depolarizing current pulse. Activation of $\mathrm{B} 37$ produced activity in B31/B32, and a late burst of spikes in B4, which corresponds to the repolarization of B31/B32. When B31/ $\mathrm{B} 32$ is hyperpolarized to prevent its activity, B37 was no longer able to induce the late burst of spikes in B4. $A_{1}$, Activation of B37 with B31/B32 at rest. $A_{2}$, Hyperpolarization of $\mathrm{B} 31 / \mathrm{B} 32$ prevents expression of the late bursts of spikes in $\mathrm{B} 4$. $A_{3}$, After hyperpolarization is removed, firing $\mathrm{B} 37$ again initiates the late burst of spikes in B4. $B$, Same recording as shown in $A_{2}$ at a faster sweep speed showing that B37 excites B4, even when $\mathrm{B} 31 / \mathrm{B} 32$ is not active, but does not elicit a large burst of activity in B31/B32.

always found in a particular region of the ganglion. Third, we never found more than 3 nonspiking cells (B31, B32, and B34) in a preparation. Fourth, we routinely recorded from these cells for up to $3 \mathrm{hr}$ without a change in stability, even when the cells were impaled with 2 electrodes. Fifth, resting potentials were uniformly greater than $60 \mathrm{mV}$. Perhaps the most convincing demonstration that the $10 \mathrm{mV}$ or smaller potentials recorded in these cells is not due to damage is that similar potentials are also recorded in cell B33, which is capable of generating conventional action potentials. In that cell, conventional action potentials are interspersed with the smaller potentials.

The nature of the small, spikelike potentials is not clear. A small number of the potentials recorded in cells B31 and B32 are coupling potentials due to action potentials in B33. However, most of the potentials appear to be from another source. They could be coupling potentials from other cells, EPSPs, or axonal spikes that fail to invade the soma. In Aplysia, all-ornone axon spikes resembling the spikelike potentials have been observed in the bag cells (Kupfermann and Kandel, 1970) and in cell C2 (Weiss et al., 1986b). Unlike B31/B32, however, C2 and the bag cells also display conventional axon potentials.

\section{Possible behavioral correlates of the patterns and their relation to plasticity of feeding behavior}

Since the major role of the buccal ganglia in Aplysia is to control feeding behavior (Kupfermann, 1974b; Cohen et al., 1978; Rosen et al., 1982; Jahan-Parwar et al., 1983), it seems likely that the newly identified cells and the patterns of activity associated with them participate in aspects of feeding. Behavioral studies (Kupfermann, 1974a; Weiss et al., 1986a) have identified 3 activity patterns that are components of feeding: biting and swallowing, which are both ingestive acts, and rejection. Although additional studics bcyond the scope of the present analysis will be required to examine the behavioral role of the newly identified cells, a number of factors suggest that pattern 1 underlies an ingestive act, while pattern 2 may underlie rejection. Previous data (Kupfermann, 1974a; Susswein et al., 1976; Weiss et al., 1986a; Schwarz et al., 1987) indicate that bite and swallow frequencies are in the same range as that seen for pattern 1. Rejection occurs at a lower frequency and is much more variable (Weiss et al., 1986a). Rejection can be triggered by stimulation of peripheral nerves, particularly the esophageal nerves (Wciss et al., 1986a). Finally, rejection is self-limiting; rejection movements cease after a few bouts (Kupfermann, personal communication). All these characteristics are consistent with the activity of pattern 2. Ultimately, however, the behavioral correlates of patterns 1 and 2 will have to be resolved by the use of chronic recording techniques (Pinsker, 1980; Kupfermann and Weiss, 1982) or by development of a semi-intact feeding preparation (Weiss et al., 1986a).

Previous behavioral studies have shown that feeding in Aplysia is modified by a number of different processes (Kupfermann, 1974a; Schwarz et al., 1987), including an associative learning paradigm having much in common with instrumental learning in higher animals (Susswein et al., 1986). Based on these studies, a model was developed suggesting that learned changes in feeding behavior occur by differentially regulating which pattern gencrator is cxpressed in response to food. In order to test this model, it is necessary to have direct access to the pattern generators that organize and initiate different feeding movements and to the sensory neurons that excite them. The present study provides significant information about a population of cells that play a major role in initiating patterned activity in the buccal ganglion. Coupling our study with previous information describing a group of primary afferents innervating the lips that can also initiate patterned activity in the buccal ganglion (Rosen et al., 1982), it may now be possible to study the mechanisms that bias an animal to respond to a stimulus with a particular behavioral pattern and to examine how the neural circuits underlying these behaviors are changed by learning.

\section{References}

Arshavsky, Yu. I., I. N. Beloozerova, G. N. Orlovsky, Yu. V. Panchin, and G. A. Pavlova (1985) Control of locomotion in the marine mollusc Clione limacina. II. Rhythmic neurons of the pedal ganglia. Exp. Brain Res. 58: 263-272.

Benson, J. A., and I. M. Cooke (1984) Driver potentials and the organization of rhythmic bursting in crustacean ganglia. Trends Neurosci. $7: 85-91$.

Cohen, J. L., K. R. Weiss, and I. Kupfermann (1978) Motor control of buccal muscles in Aplysia. J. Neurophysiol. 41: 157-180.

Croll, K. P., M. P. Kovac, and W. J. Davis (1985) Neural mechanisms of motor program switching in the mollusc Pleurobranchaea. II. Role 
of the ventral white cell, anterior ventral, and $\mathrm{B} 3$ buccal neurons. J. Neurosci. 5: 56-63.

Dowling, J. E. (1970) Organization of vertebrate retinas. Invest. Ophthamol. 9: 655-680.

Elliot, C. J. H., and P. R. Benjamin (1985) Interactions of patterngenerating interneurons controlling feeding in Lymnaea stagnalis. $\mathrm{J}$. Neurophysiol. 54: 1396-1411.

Fiore, L., and J.-M. Meunier (1979) Synaptic connections and functionat organization in Aplysia buccal ganglia. J. Neurobiol. 10: 1329.

Gardner, D. (1977) Interconnections of identified multiaction interneurons in the buccal ganglia of Aplysia. J. Neurophysiol. 40: 349361.

Gardner, D., and E. Kandel (1977) Physiological and kinetic properties of cholinergic receptors activated by multiaction interneurons in buccal ganglia of Aplysia. J. Neurophysiol. 40: 333-348.

Jahan-Parwar, B., and S. M. Fredman (1983) Control of extrinsic fecding muscles in Aplysia. J. Neurophysiol. 49: 1481-1503.

Jahan-Parwar, B., A. H. Wilson, and S. M. Fredman (1983) Role of proprioceptive reflexes in control of feeding muscles of Aplysia. J. Neurophysiol. 49: 1469-1480.

Kupfermann, I. (1974a) Feeding in Aplysia: A simple system for the study of motivation. Behav. Biol. 10: 1-26.

Kupfermann, I. (1974b) Dissociation of the apetitive and consumatory phases of feeding behavior in Aplysia: A lesion study. Behav. Biol. 10: 89-97.

Kupfermann, I., and E. R. Kandel (1970) Electrophysiological properties and functional interconnections of two symmetrical neurosecretory clusters (Bag cells) in abdominal ganglion of Aplysia. J. Neurophysiol. 33: 865-876.

Kupfermann, I., and I. Pinsker (1968) A behavioral modification of the fecding reflex in Aplysia californica. Commun. Behav. Biol. A. 2 ; $13-17$.

Kupfermann, I., and K. R. Weiss (1982) Activity of an identified serotonergic neuron in free moving Aplysia correlates with behavioral arousal. Brain Res. 241: 334-337.

Lloyd, P. E., I. Kupfermann, and K. R. Weiss (1984) Evidence for parallel actions of a molluscan neuropeptide $\left(\mathrm{SCP}_{\mathrm{B}}\right)$ and serotonin in mediating arousal in Aplysia. Proc. Natl. Acad. Sci. USA 81: 29342937.

McCrohan, C. R. (1985) Initiation of feeding motor output by an identified interneurone in the snail Lymnaea stagnalis. J. Exp. Biol. 113: 351-366.

Pearson, K. R., and C. R. Fourtner (1975) Non-spiking interneurons in walking system of the cockroach. J. Neurophysiol. 38: 33-52.

Pinskcr, H. M. (1980) Neuroethological analysis of information processing during behavior. In Information Processing in the Nervous System, H. M. Pinsker and W. D. Willis, eds., pp. 285-312, Raven, New York.

Rose, R. M., and P. R. Benjamin (1981) Interneuronal control of feeding in the pond snail Lymnaea stagnalis. II. The interneuronal mechanism generating feeding cycles. J. Exp. Biol. 92: 203-228.

Rosen, S. C., K. R. Weiss, and I. Kupfermann (1979) Response properties and synaptic connections of mechanoafferent neurons in cerebral ganglion of Aplysia. J. Neurophysiol. 42: 954-974.

Rosen, S. C., K. R. Weiss, J. L. Cohen, and I. Kupfermann (1982) Interganglionic cerebral-buccal mechanoafferents of Aplysia: Receptive fields and synaptic connections to different classes of neurons involved in feeding behavior. J. Neurophysiol. 48: 271-288.

Schwarz, M., and A. J. Susswein (1986) Identification of the neural pathway for reinforcement of feeding when Aplysia learn that food is inedible. J. Neurosci. 6: 1528-1536.

Schwarz, M., S. Markovich, and A. J. Susswein (1988) Inhibition of feeding in Aplysia by associative learning, satiation and sustained lip stimulation is produced by different mechanisms. Behav. Neurosci. 102: 124-133.

Susswein, A. J., and J. H. Byrne (1986) Expression of different patterns of motor activity in the buccal ganglion of Aplysia. Soc. Neurosci. Abstr. 12: 96.

Susswein, A. J., and I. Kupfermann (1975a) Bulk as a stimulus for satiation in Aplysia. Behav. Biol. 13: 203-209.

Susswein, A. J., and I. Kupfermann (1975b) Localization of bulk stimuli underlying satiation in Aplysia. J. Comp. Physiol. 101: 309328.

Susswein, A. J., and M. Schwarz (1983) A learned change of response to inedible food in Aplysia. Behav. Neural Biol. 39: 1-6.

Susswein, A. J., I. Kupfermann, and K. R. Weiss (1976) The stimulus control of biting in Aplysia. J. Comp. Physiol. 108: 75-96.

Susswein, A. J., K. R. Weiss, and I. Kupfermann (1978) The effects of food arousal on latency of biting in Aplysia. J. Comp. Physiol. 123: $31-41$.

Susswein, A. J., M. Schwarz, and E. Feldman (1986) Learned changes of feeding behavior in Aplysia in response to edible and inedible foods. J. Neurosci. 6: 1513-1527.

Weiss, K. R., J. L. Cohen, and I. Kupfermann (1978) Modulatory control of buccal musculature by a serotonergic neuron (metacerebral cell) in Aplysia. J. Neurophysiol. 41: 181-203.

Weiss, K. R., U. T. Koch, J. Koester, D. E. Mandelbaum, and I. Kupfermann (1981) Neural and molecular mechanisms of food induced arousal in Aplvsia californica. In Adv. Physiol. Sci., Vol. 23, Neurobiology of Invertebrates, J. Salanki, ed., pp. 305-344, Pergamon, New York.

Weiss, K. R., H. J. Chiel, U. Koch, and I. Kupfermann (1986a) Activity of an identified histaminergic neuron and its possible role in arousal of feeding behavior in semi-intact Aplysia. J. Neurosci. 6: 2403-2415.

Weiss, K. R., H. J. Chiel, and I. Kupfermann (1986b) Sensory function and gating of histaminergic neuron $\mathrm{C} 2$ in Aplysia. J. Neurosci. 6: $2416-2426$ 